\title{
STRATIGRAPHY AND PETROGRAPHY OF HETTANGIAN TO SINEMURIAN LACUSTRINE CARBONATES OF THE GLEN CANYON GROUP, WASHINGTON COUNTY (SW UTAH)
}

Samuel A. Abdala, Kevin E. Nick, H. Paul Buchheim samuel.abdala@gmail.com 

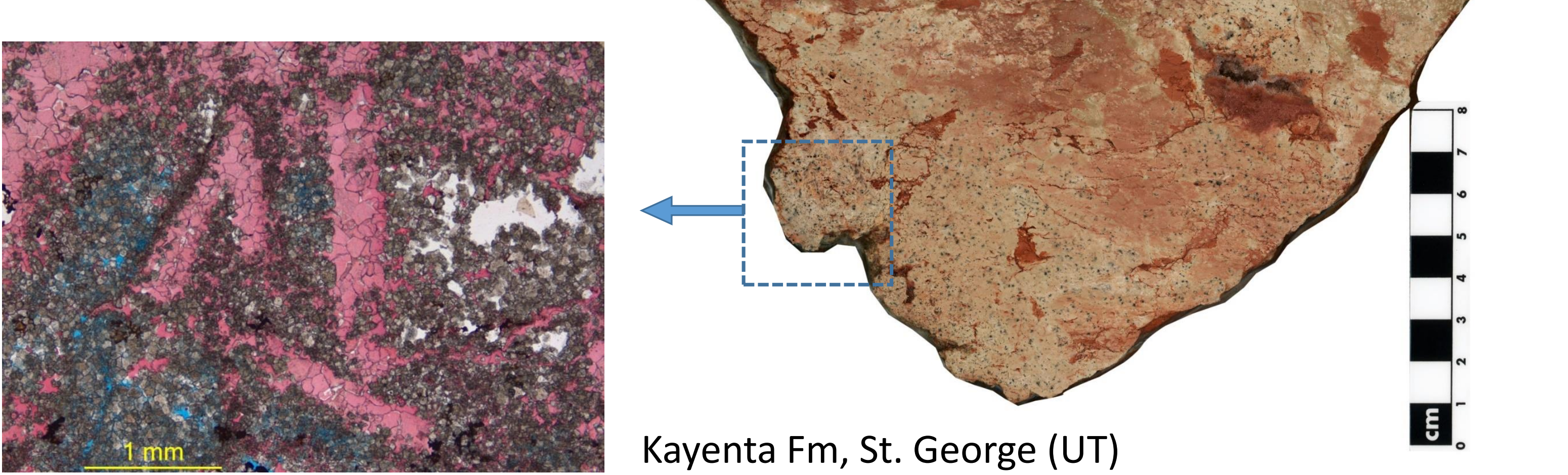

Kayenta Fm, St. George (UT) 


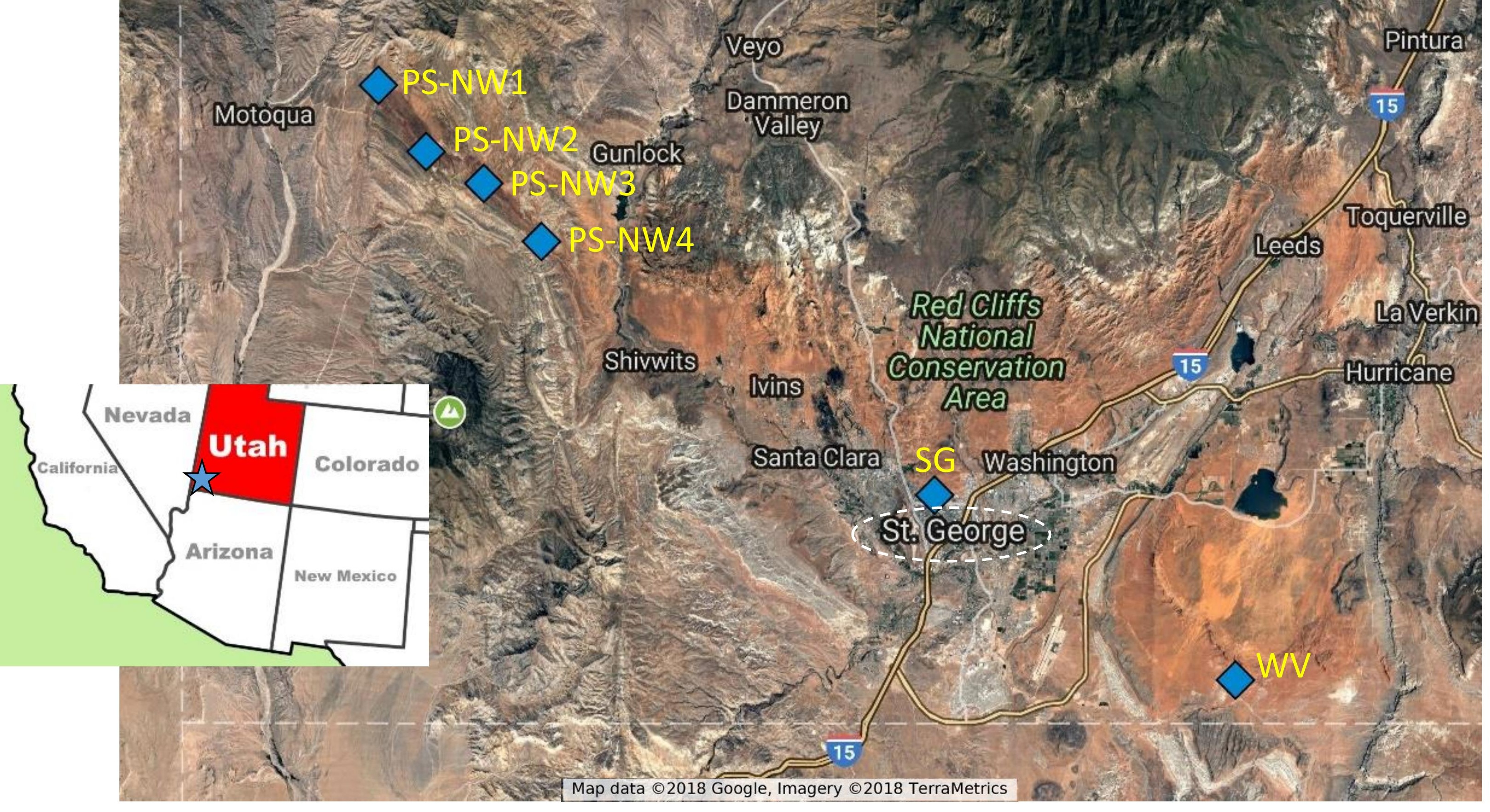



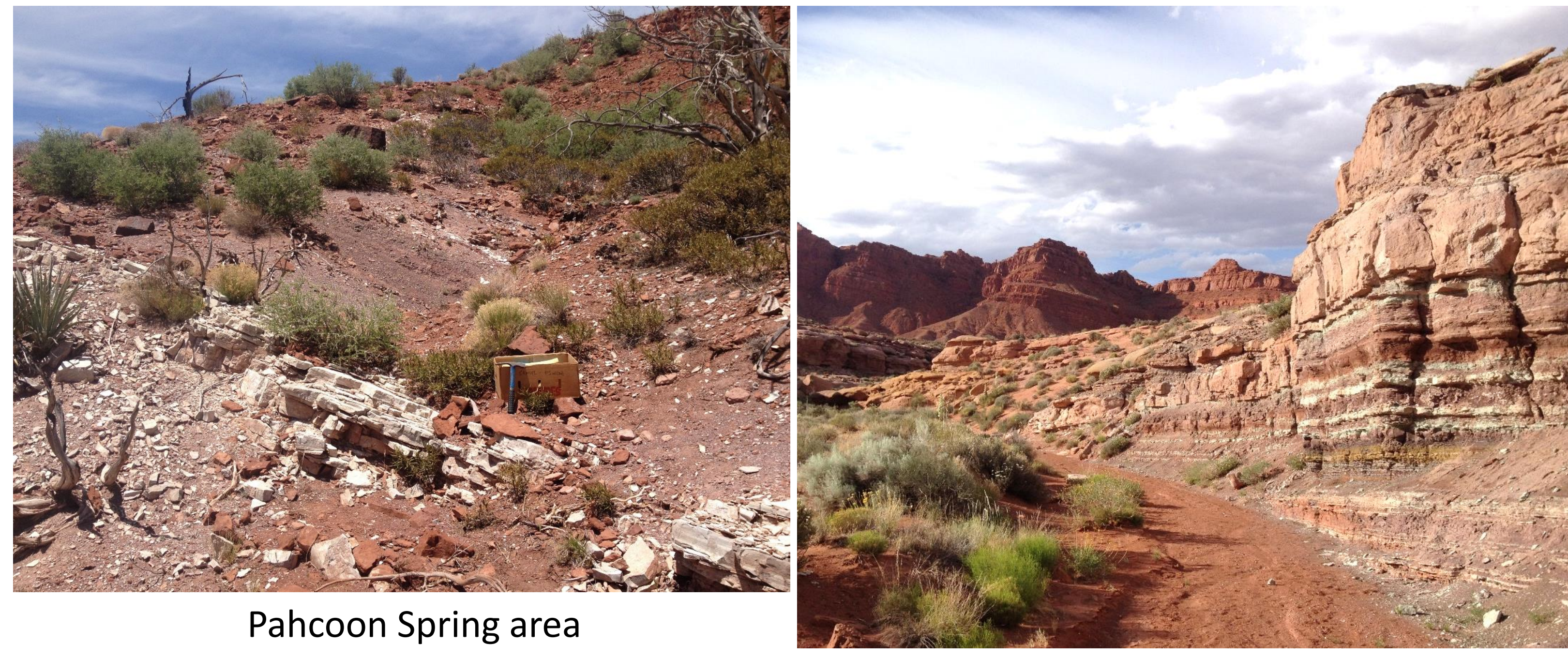

Warner Valley area 


\section{Stratigraphy}

- Carbonate beds 2 to 60 $\mathrm{cm}$ thick

- [Carbonate : Siliciclastic] in Whitmore Point $\mathrm{Mbr}$ $(1: 33)$ < Kayenta Fm (1:6)

- Different fluvial systems

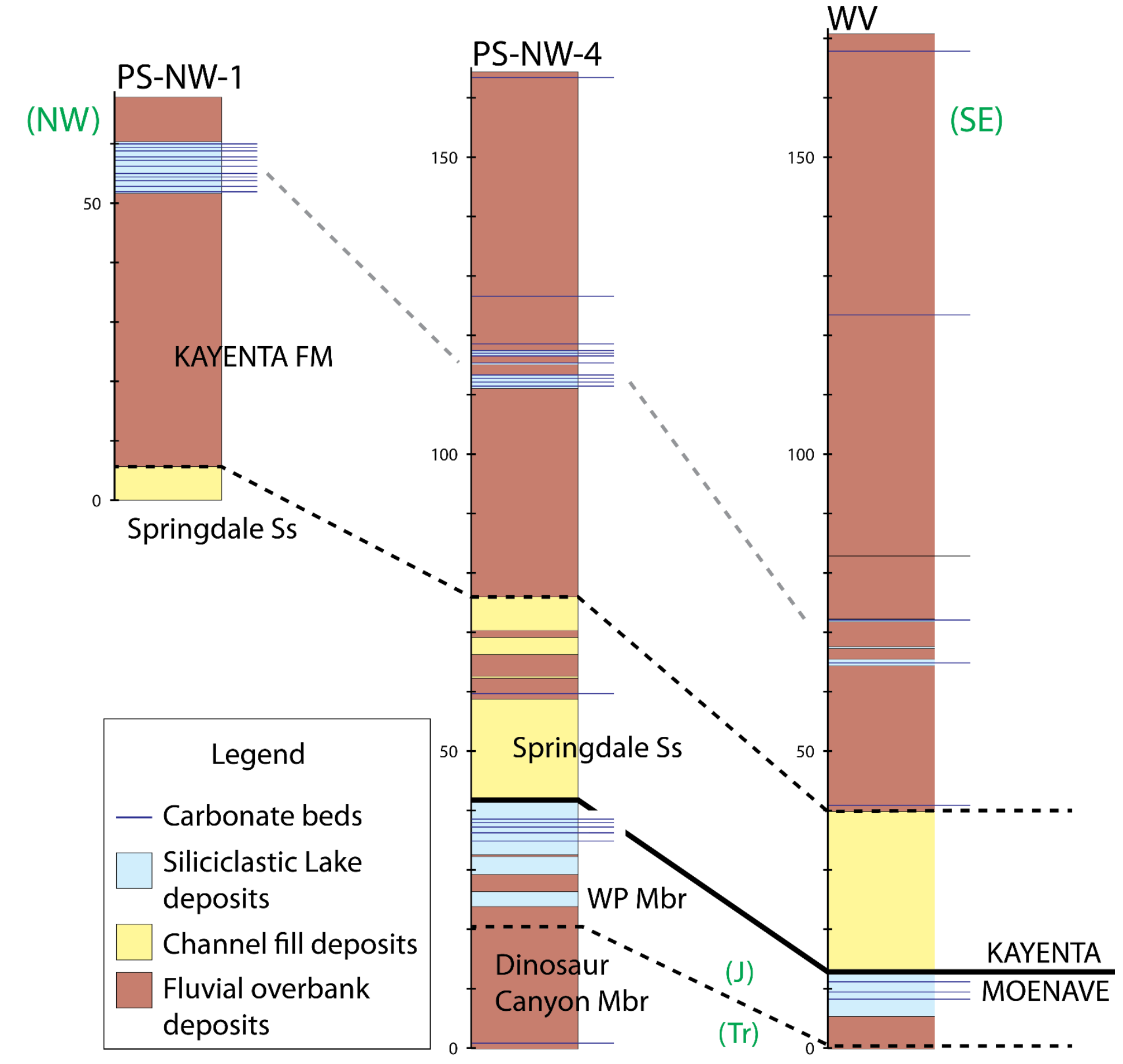




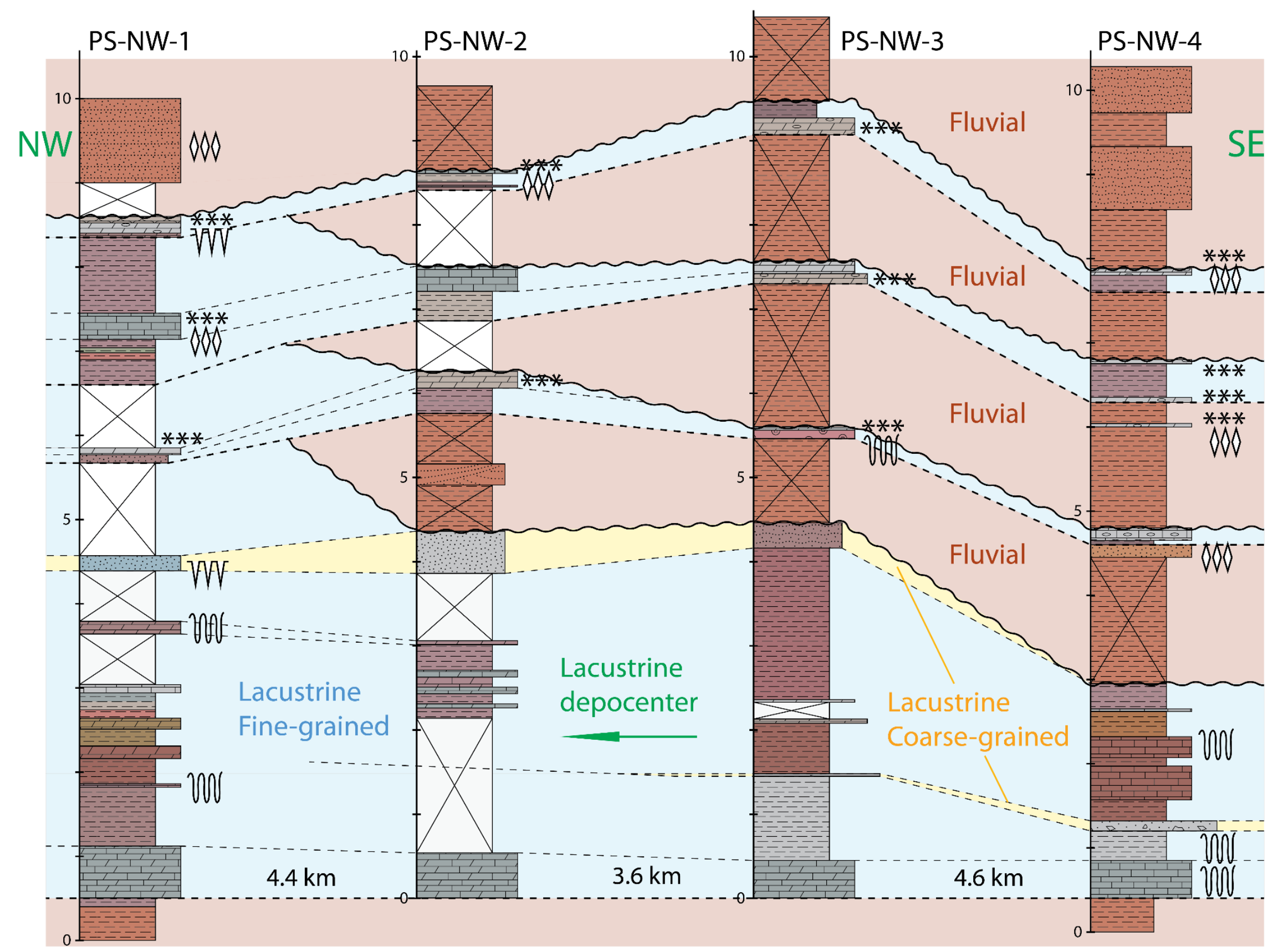

KAYENTA FM

- Lacustrine depocenter to NW

- Replaced by fluvial red-bed deposits

- Lake margin deposits less significant

*** Chert UOS Sulfate growth WV Desiccation cracks WOO Bioturbation

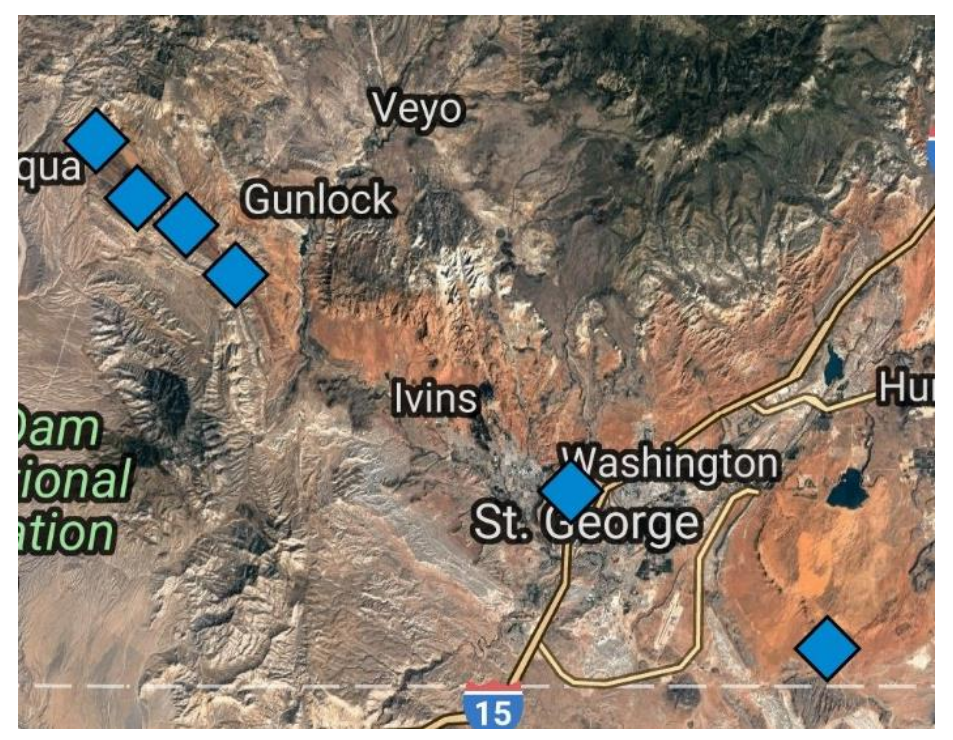


Lithologies and fossils

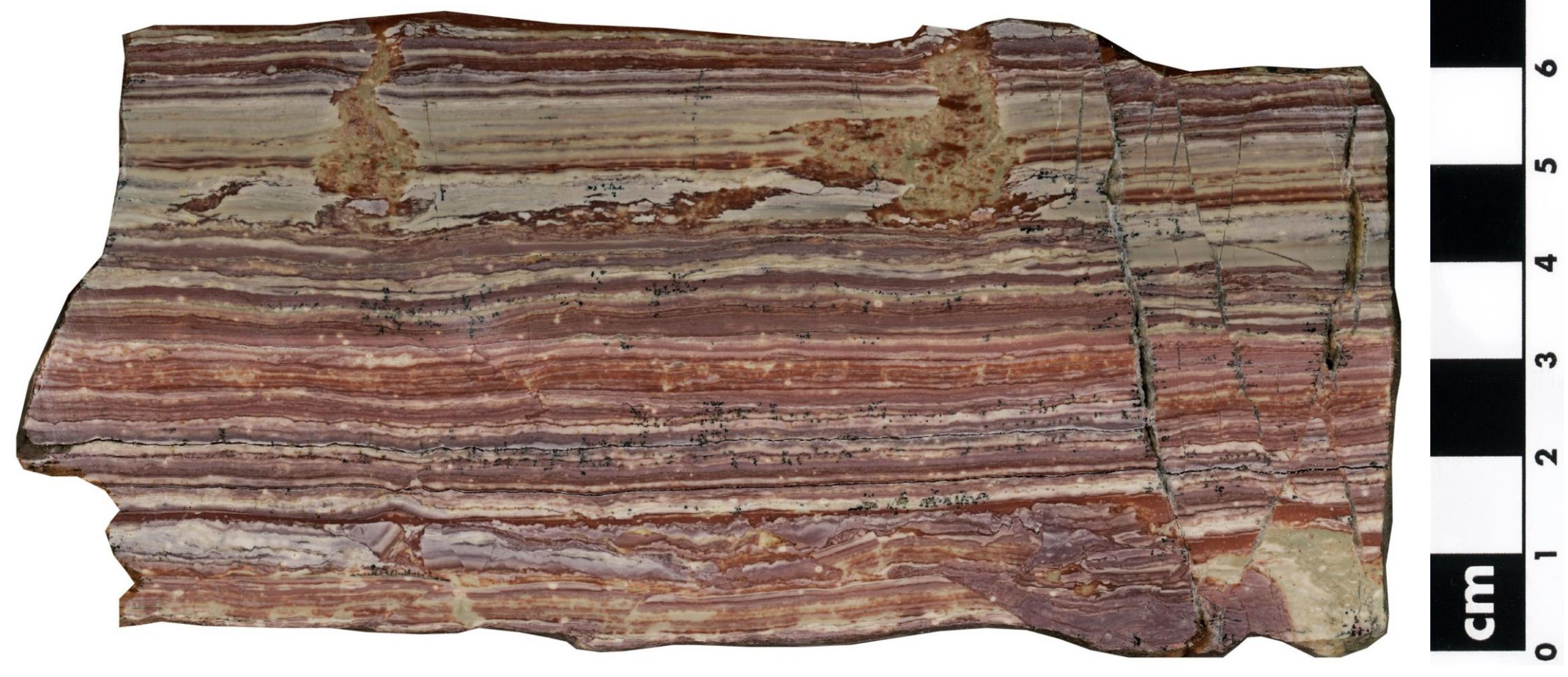

PS-NW4-A, (Kayenta) 


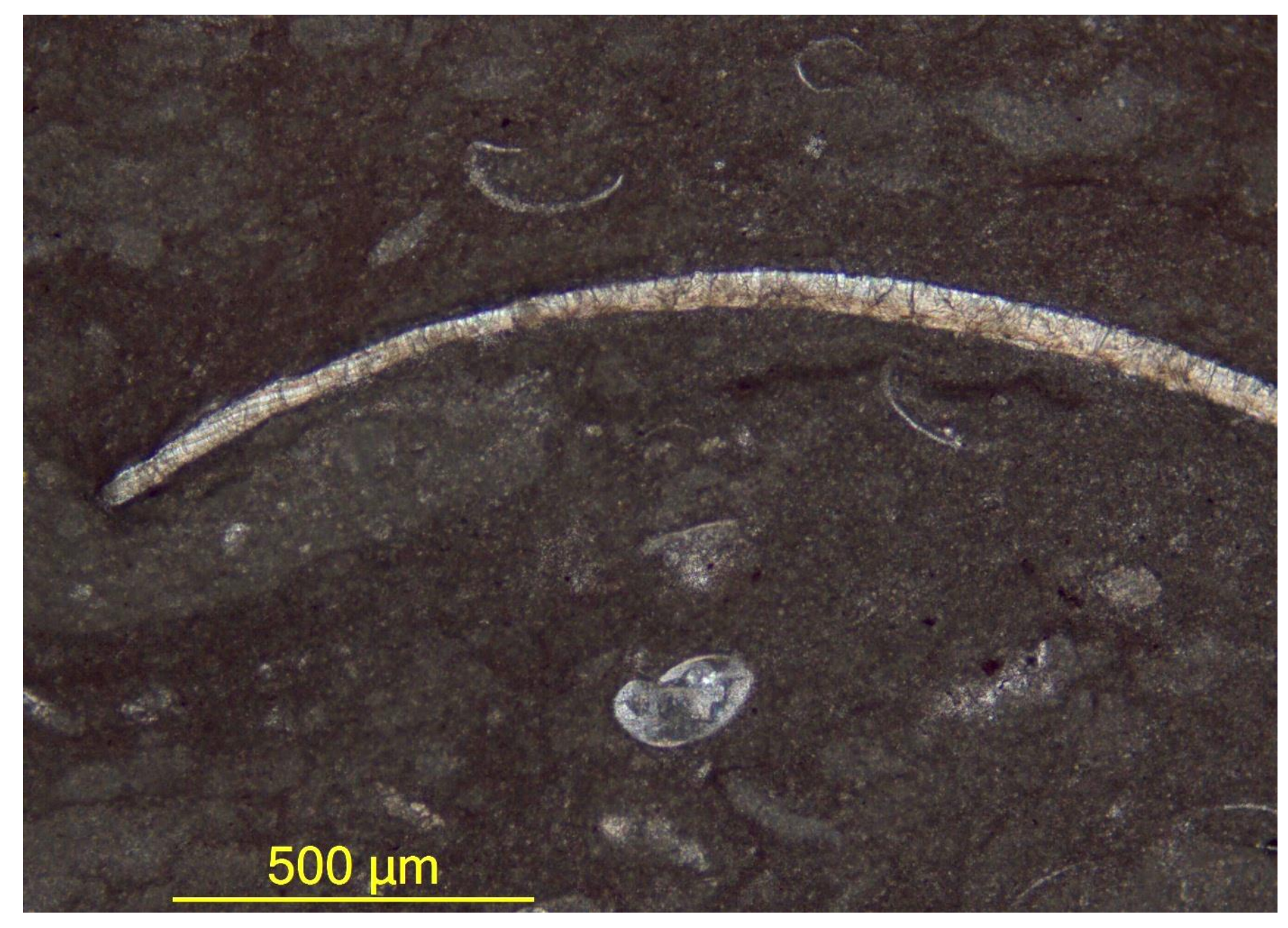

PS-NW4-C (Kayenta)

WV-Sd1 (Kayenta) 


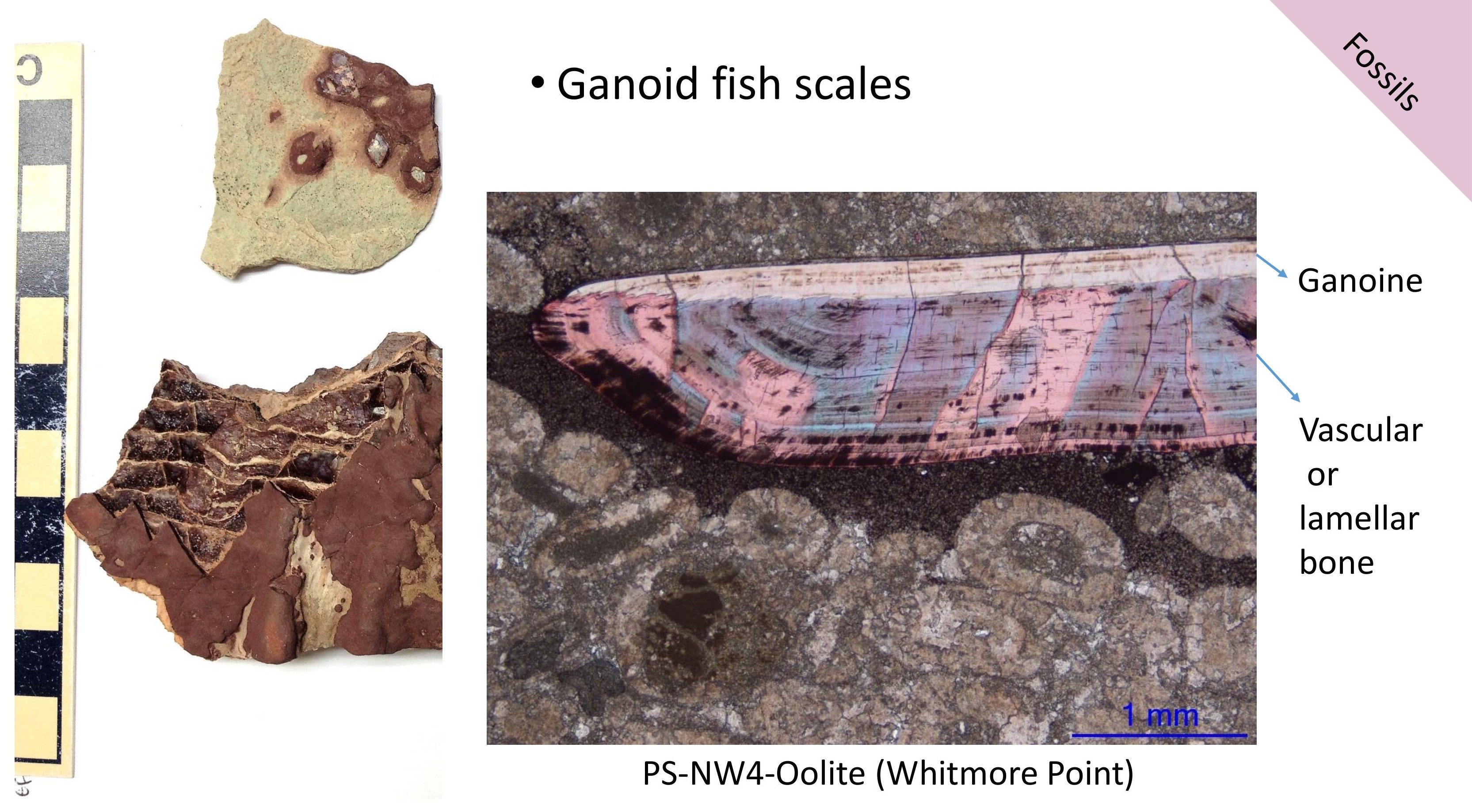




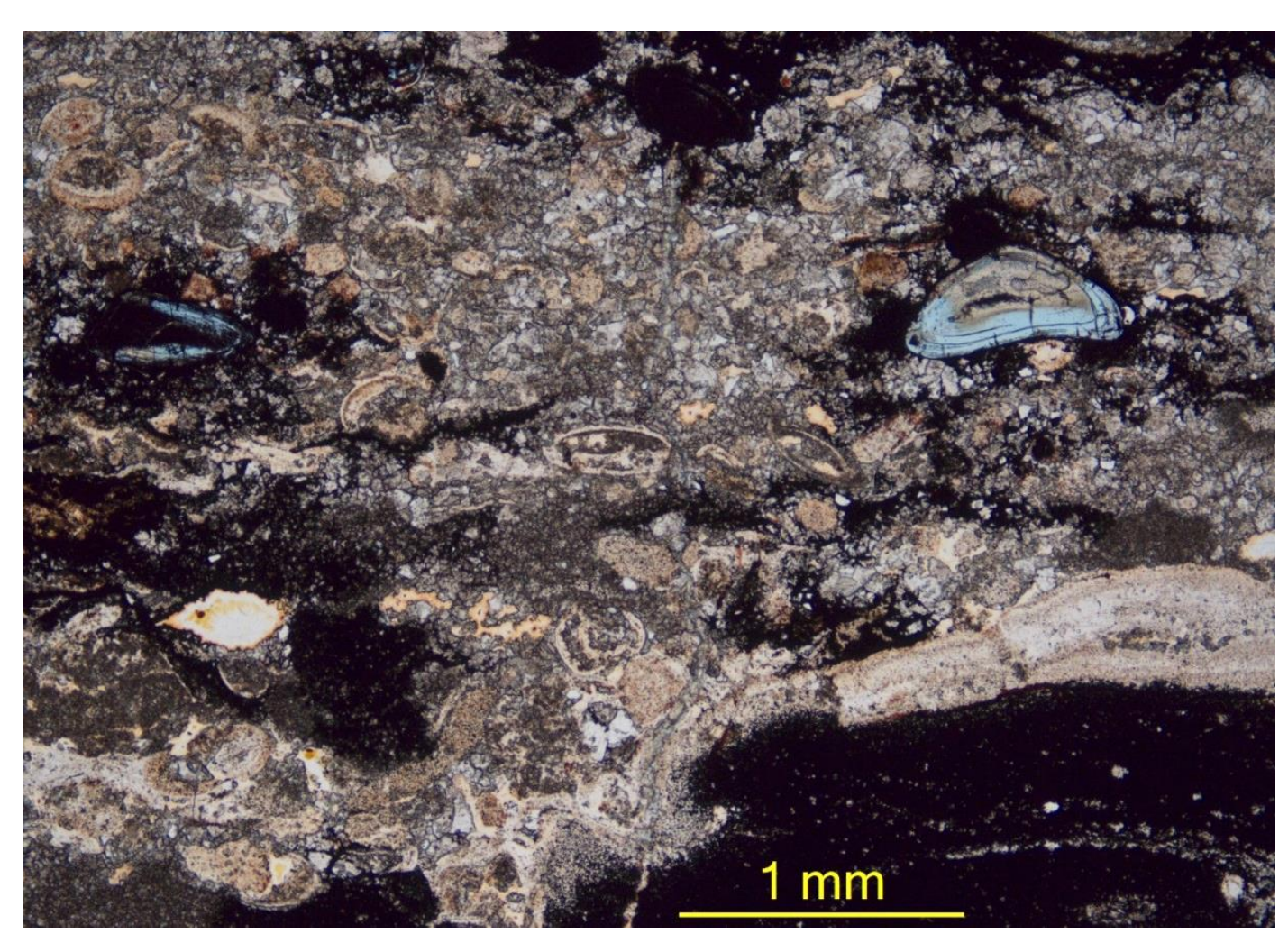

WV-WP1

(Whitmore Point)

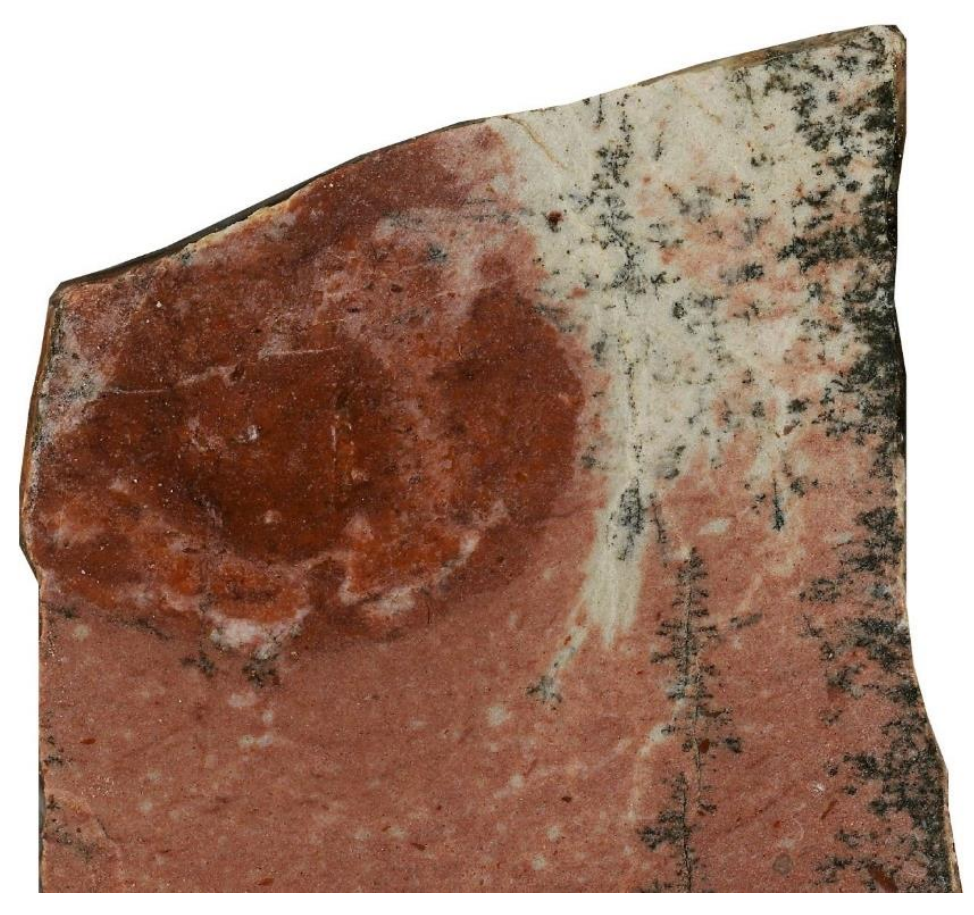

PS-NW4-Delta (Whitmore Point)

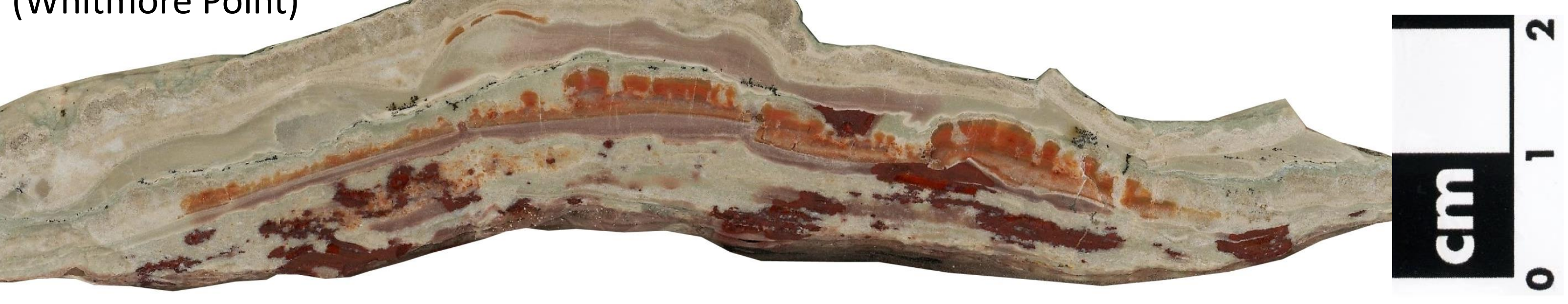



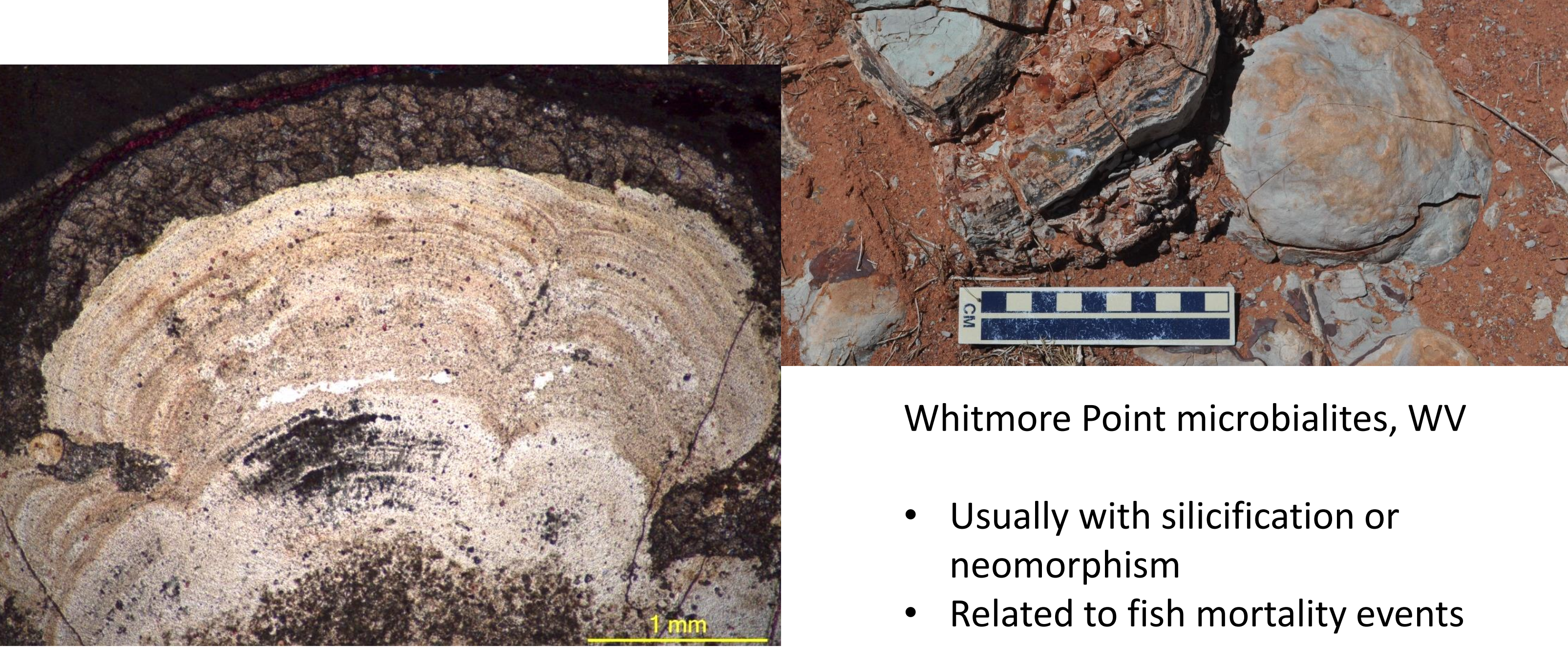

Whitmore Point microbialites, WV

- Usually with silicification or neomorphism

- Related to fish mortality events 


\section{Alveolar-septal; root textures}

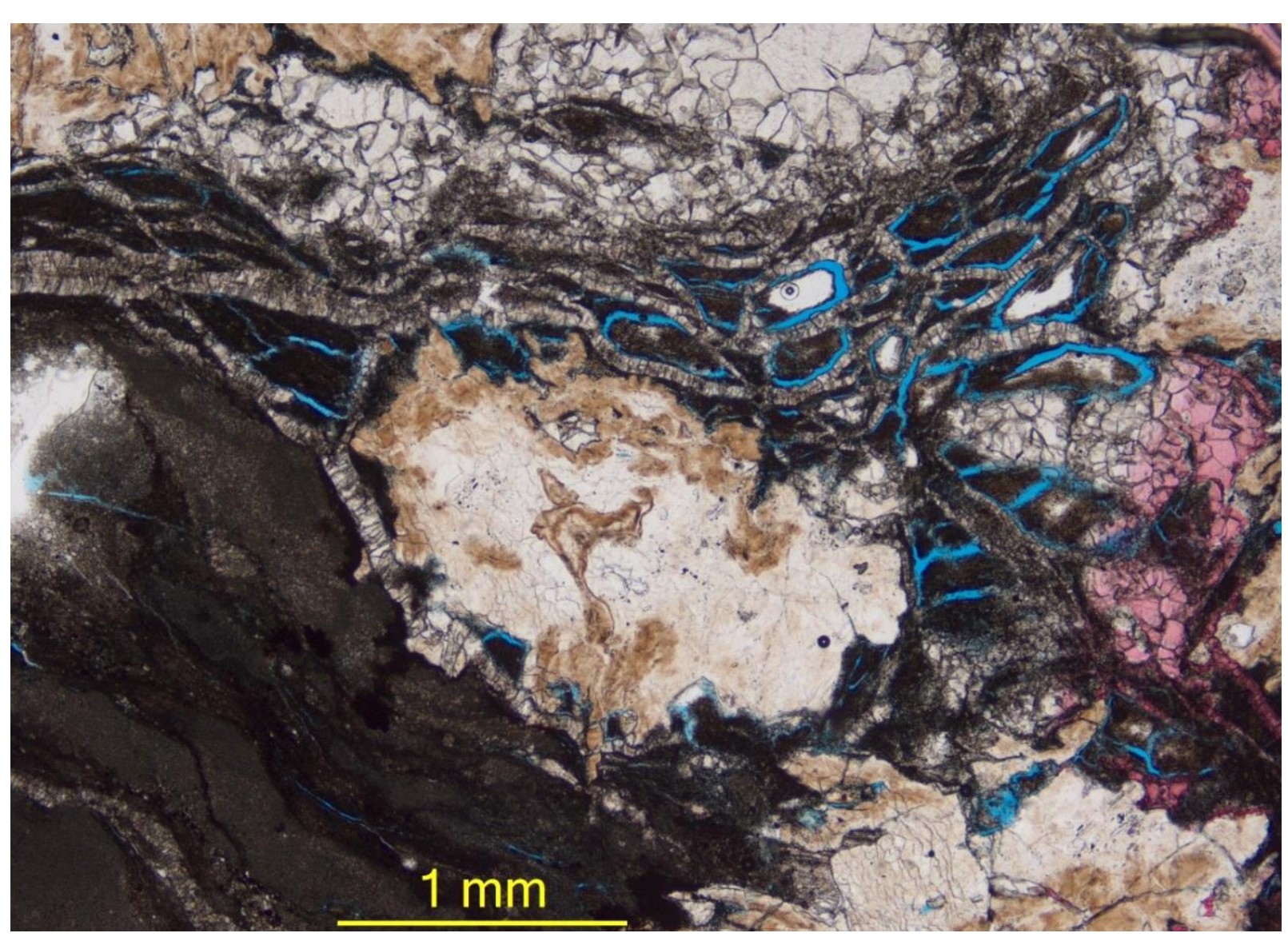

PS-NW4-4 (Kayenta)

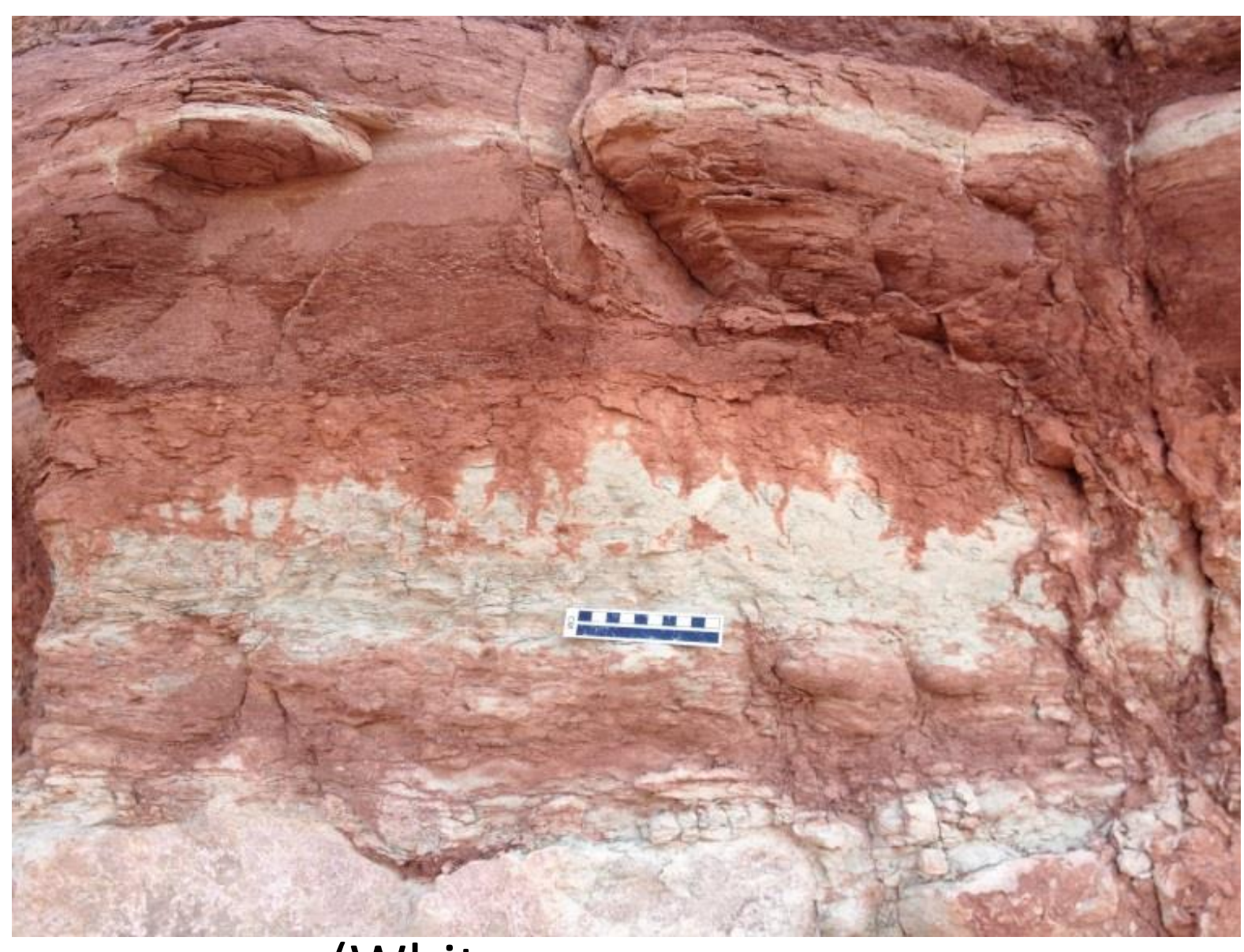

(Whitmore

Point) WV 
Circumgranular cracks and nodulization

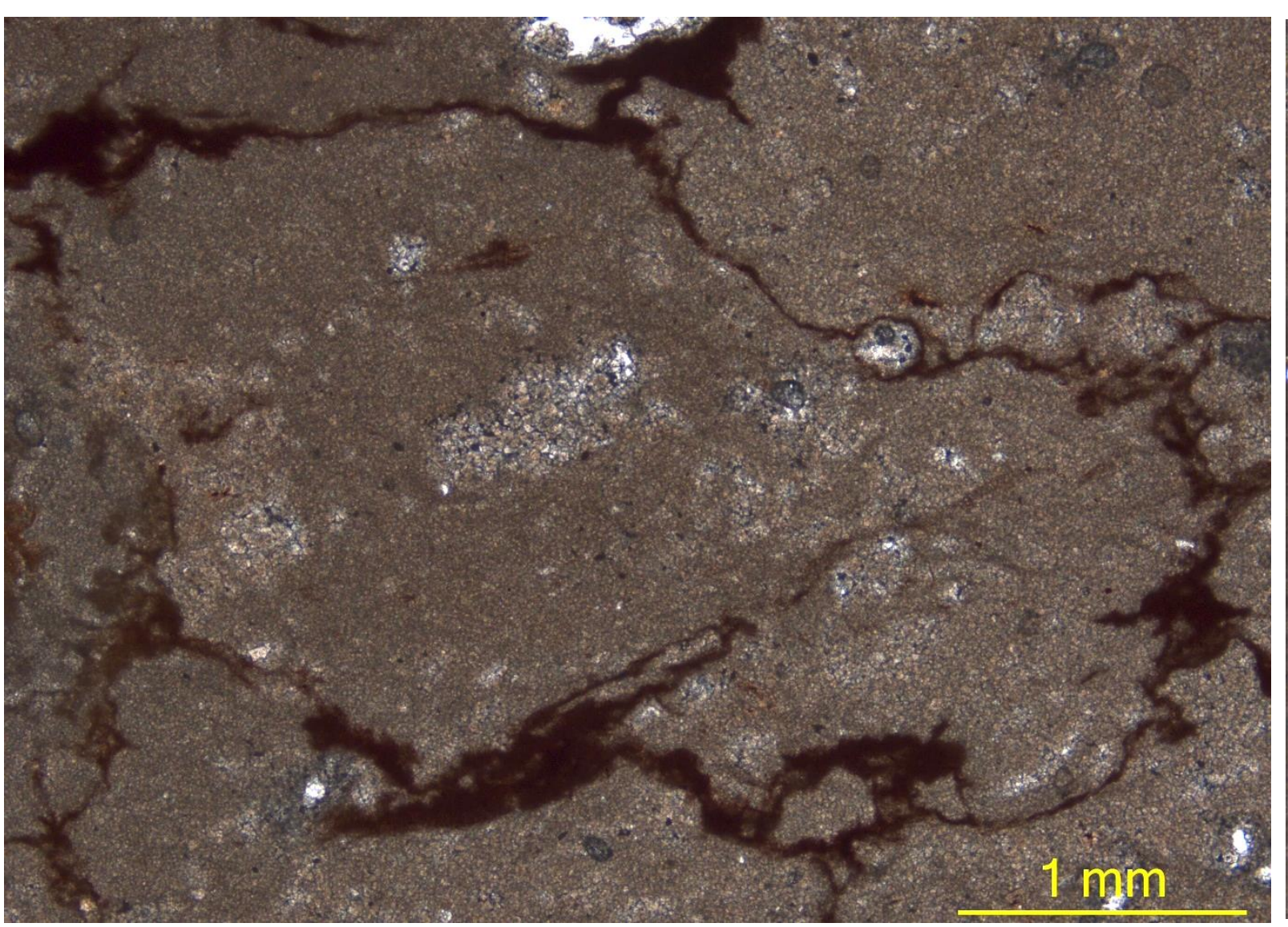

K (Kayenta), St. George

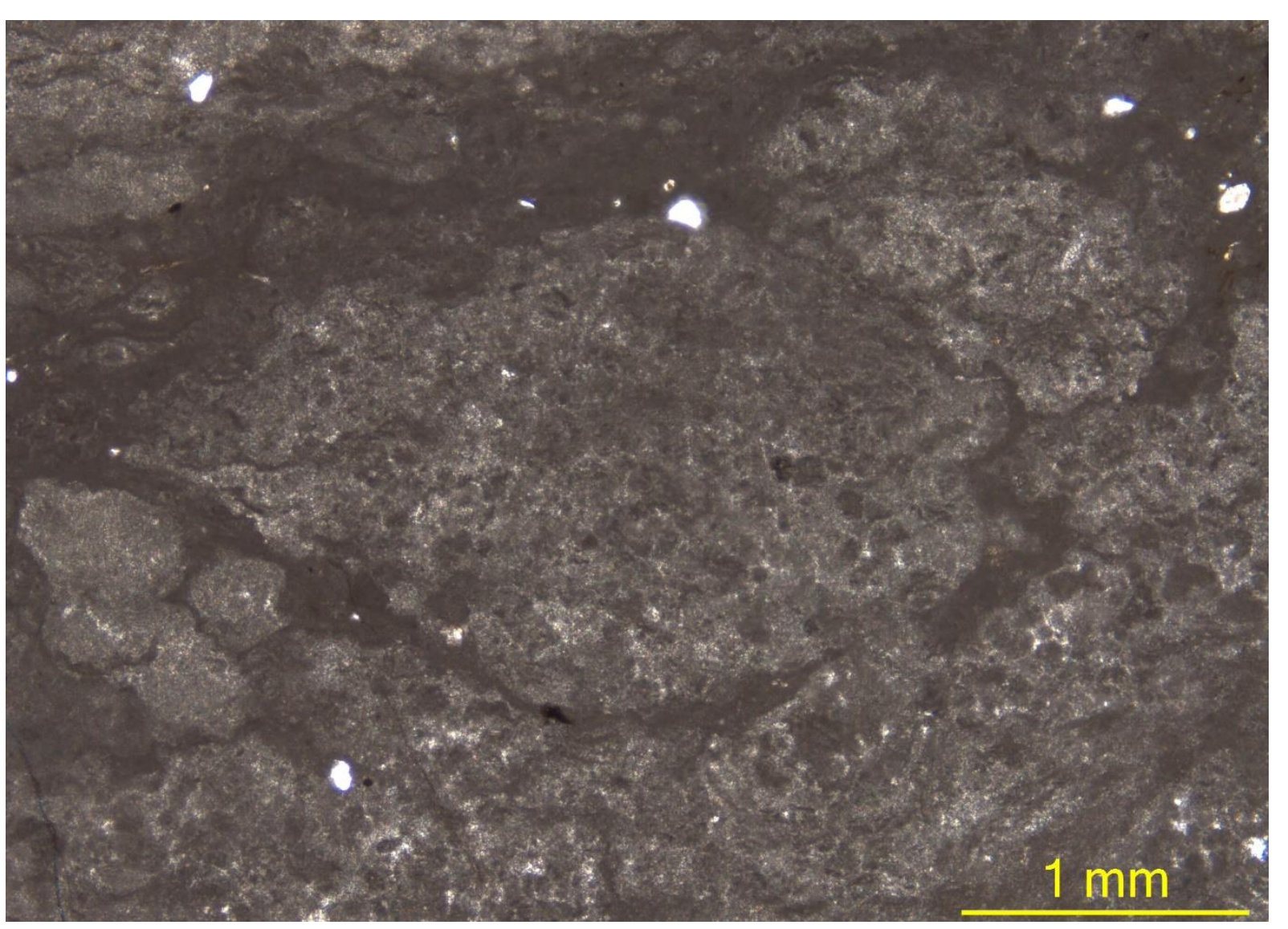

M-2 (Kayenta), Kanab 


\section{Sulfate-related}

features

- More common in the Kayenta Fm.

- Evaporative environment
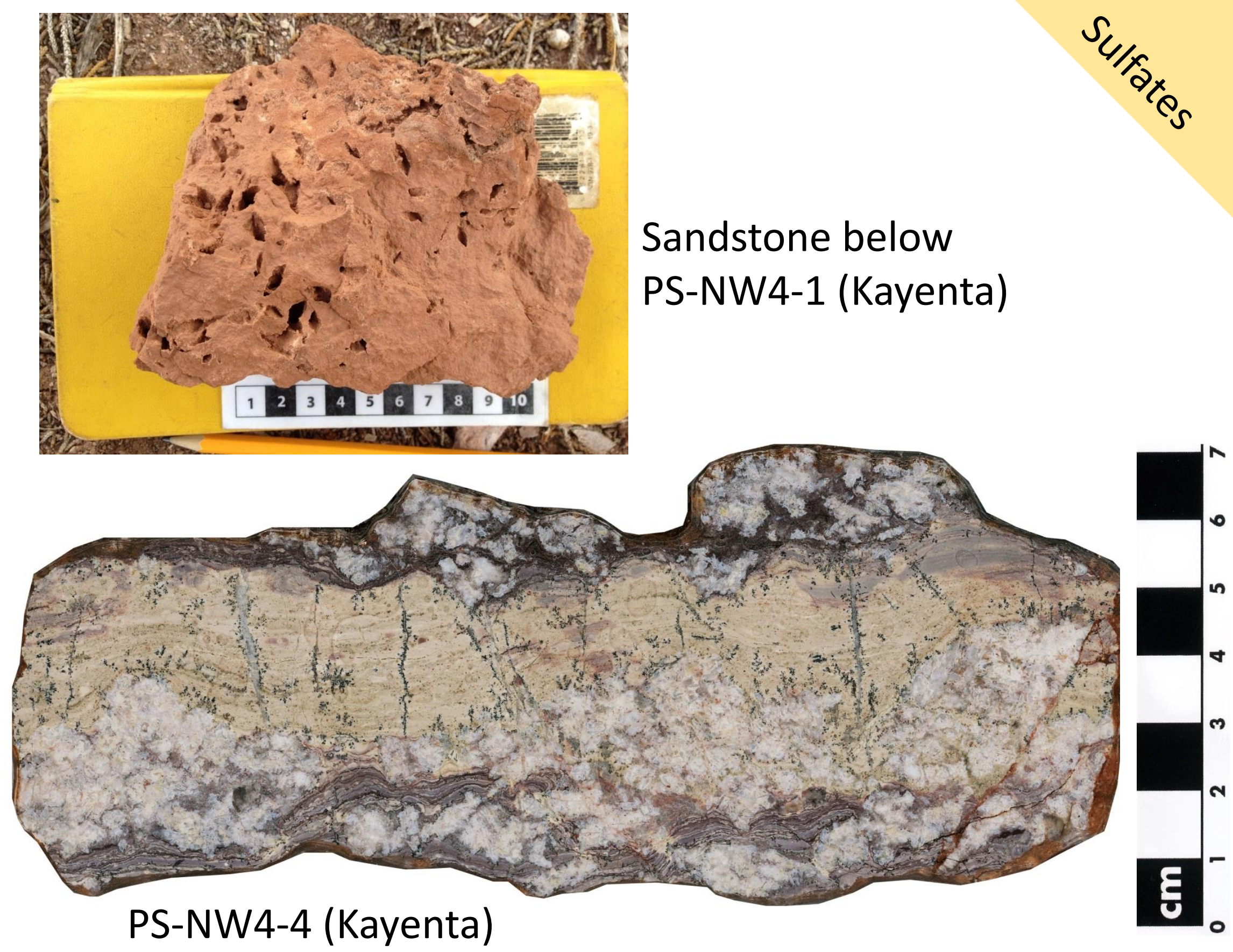

Sandstone below

PS-NW4-1 (Kayenta)

$$
\text { PS-NW4-4 (Kayenta) }
$$

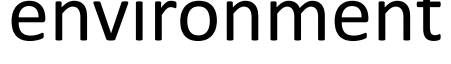




\section{Cauliflower chert

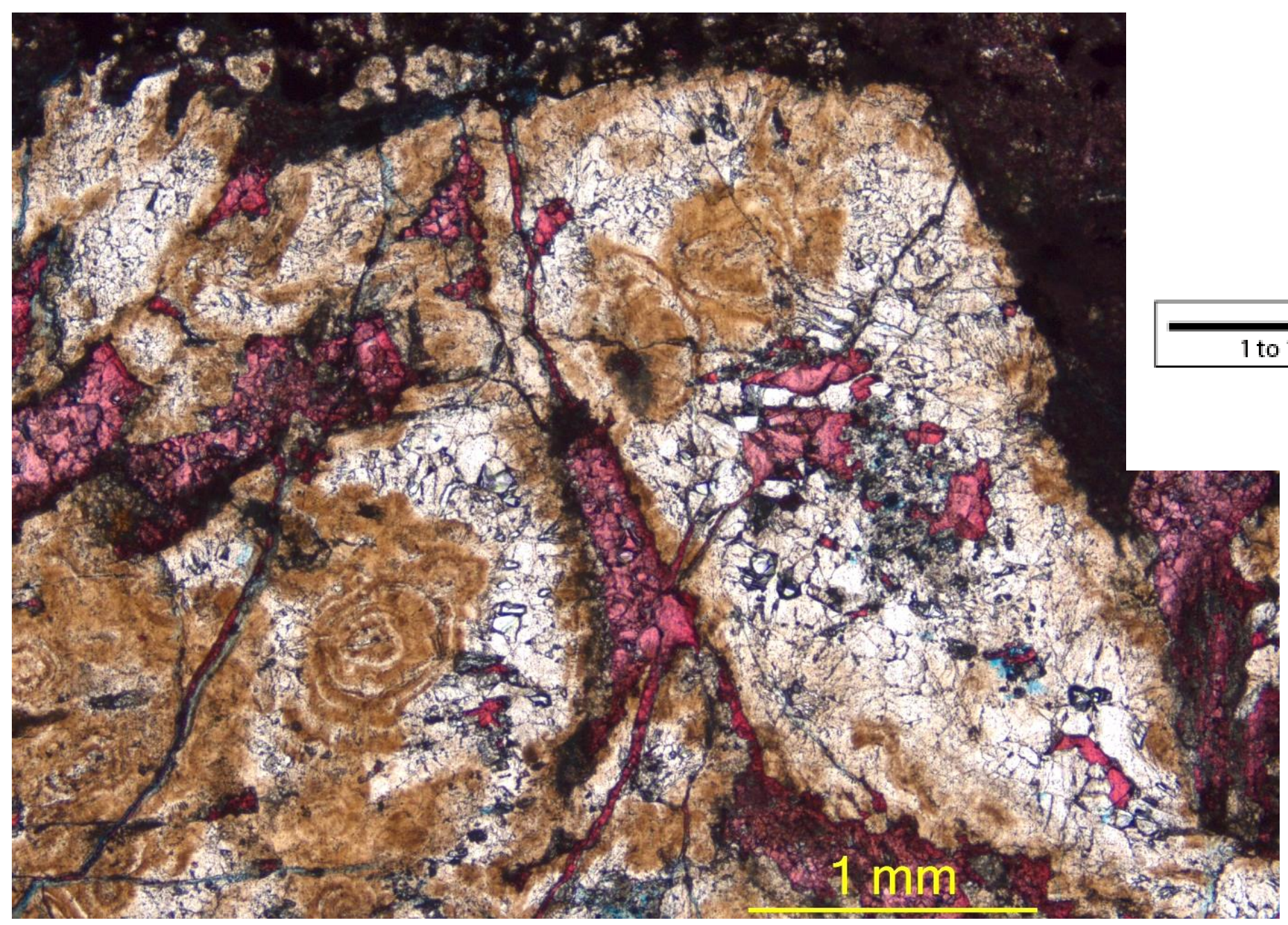
Milliken (1979)

- John Warren, from 


\section{Magadi-type chert, length-slow chalcedony}

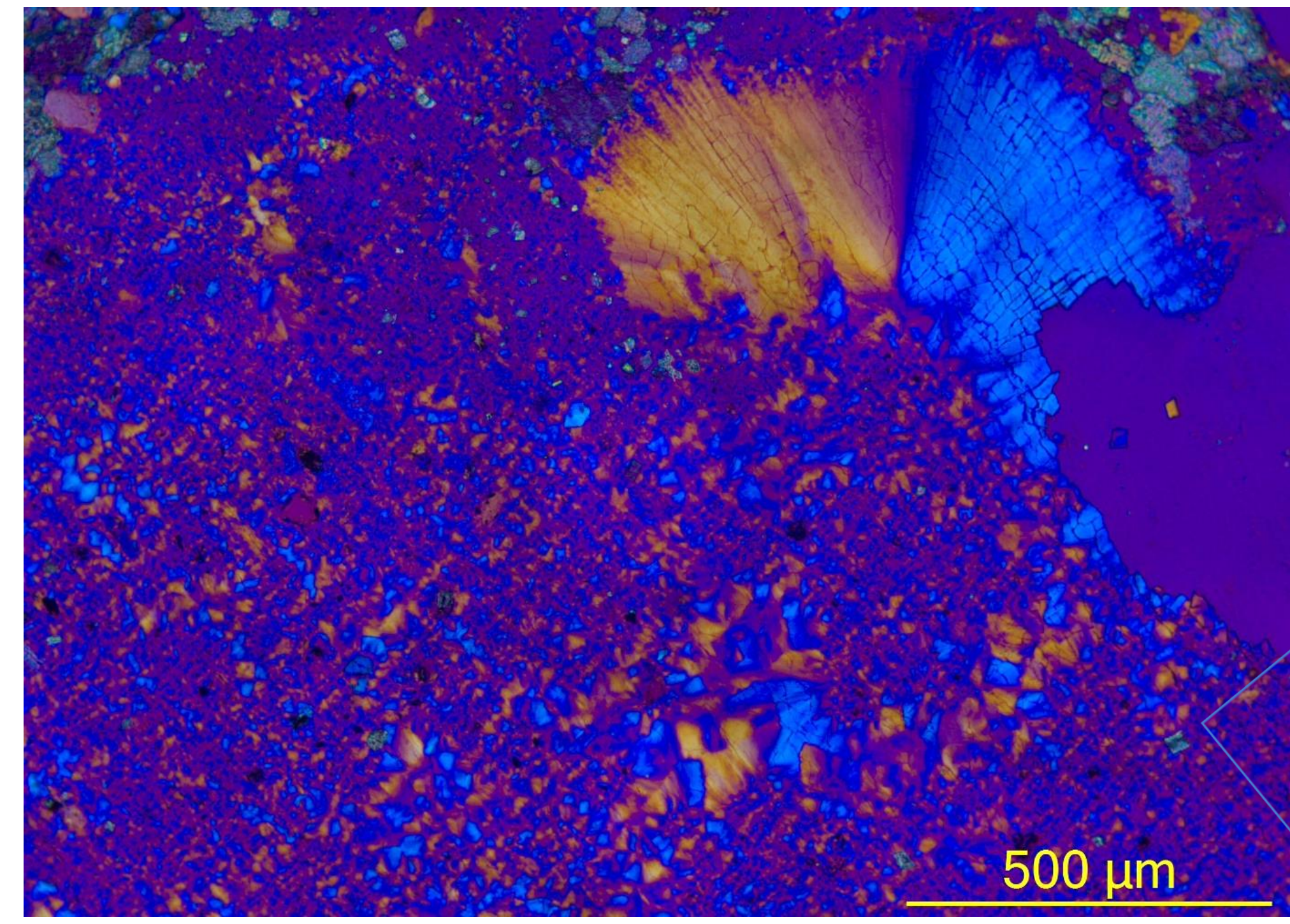

- Length-slow chalcedony (quartzine or lutecite): alkaline or sulfate-rich environments

Folk and Pittman (1971) 


\section{Petrofabrics and paragenesis timing}

- Eogenesis: pedogenesis, sulfates, chert, silicification, dolomitization

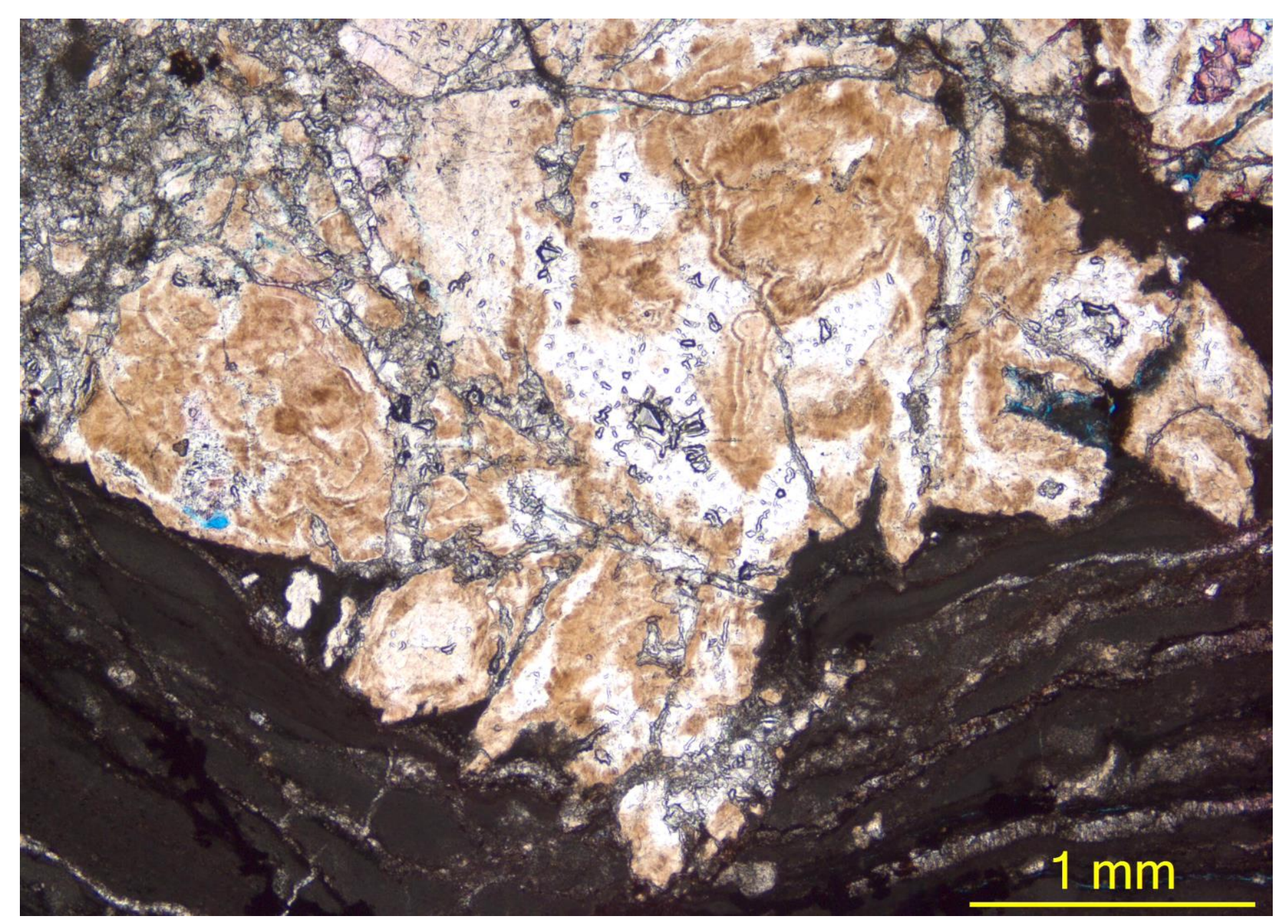

(Kayenta) 


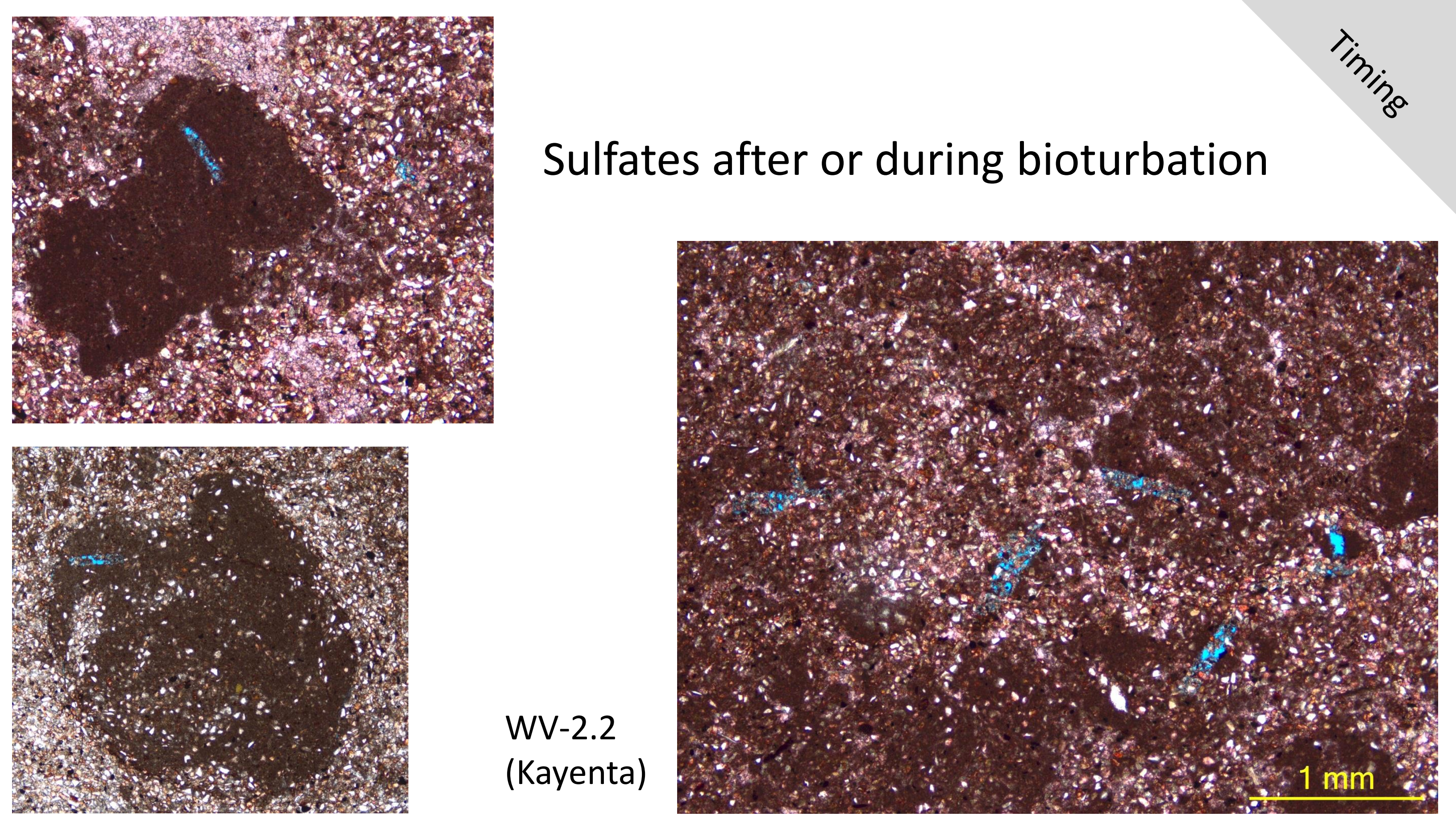




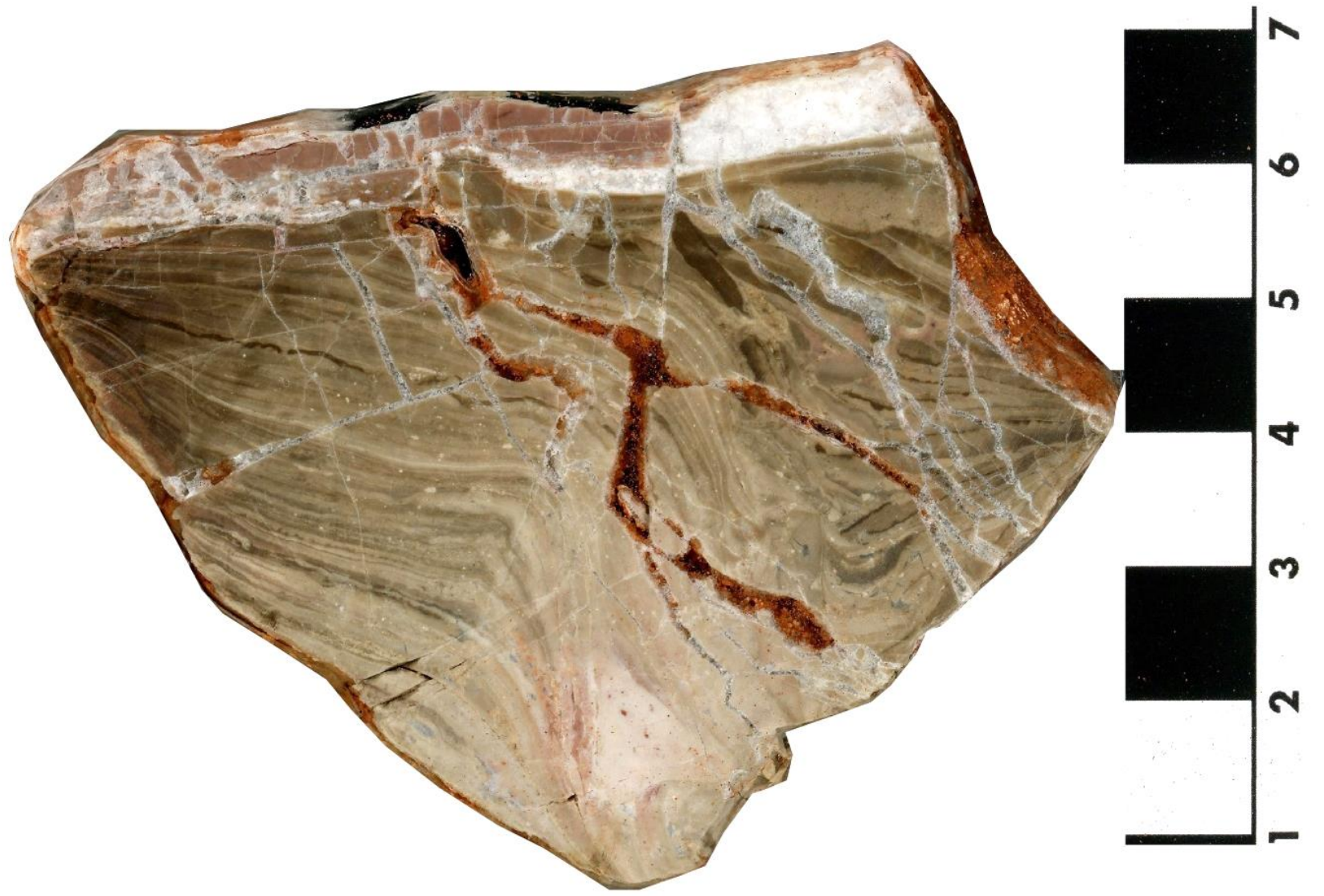

PS-NW4-2 (Kayenta)

- Early silicification features: Bustillo (2010)

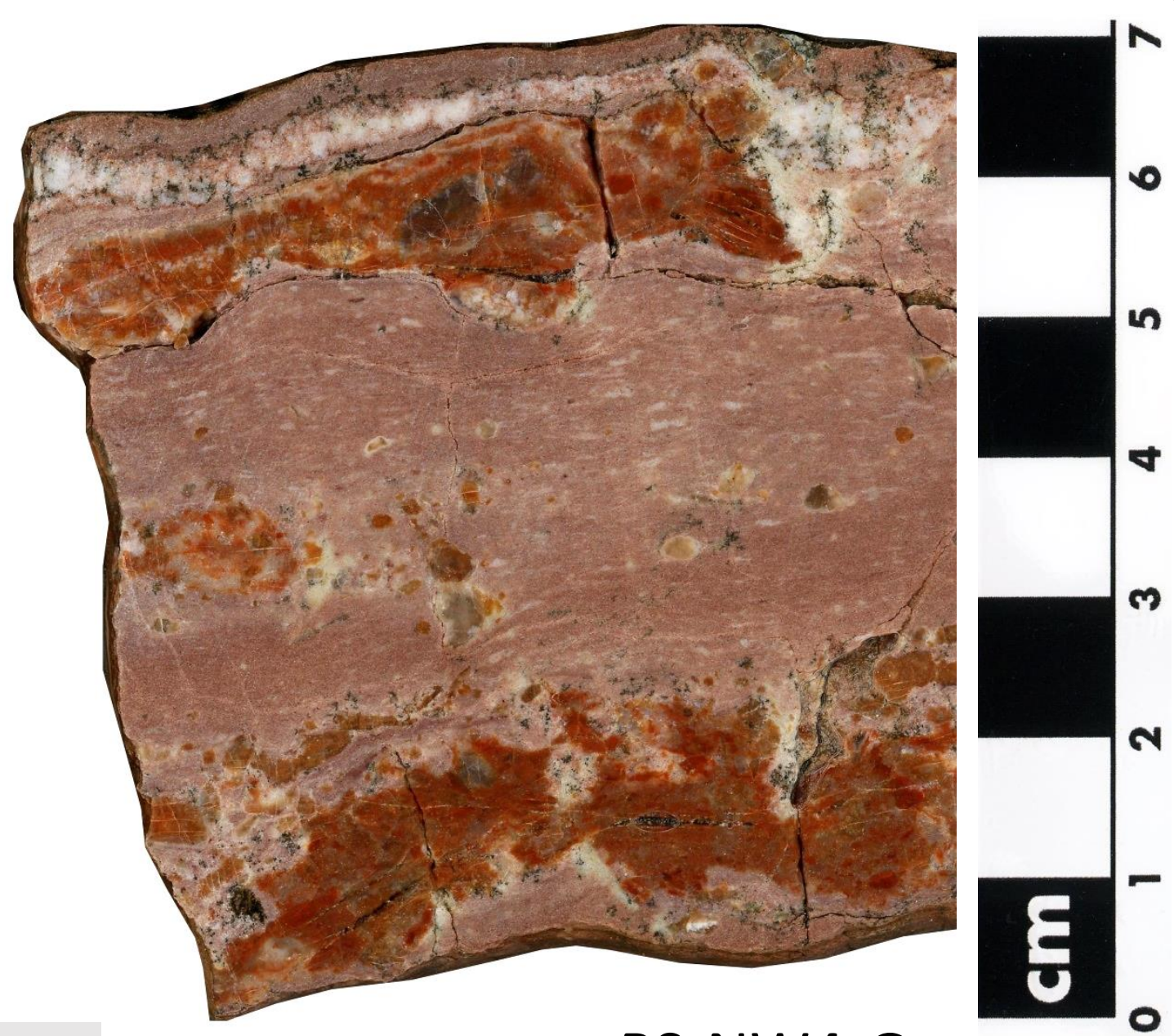

PS-NW4-Gamma (Whitmore Point) 
Silica: at least 2 phases

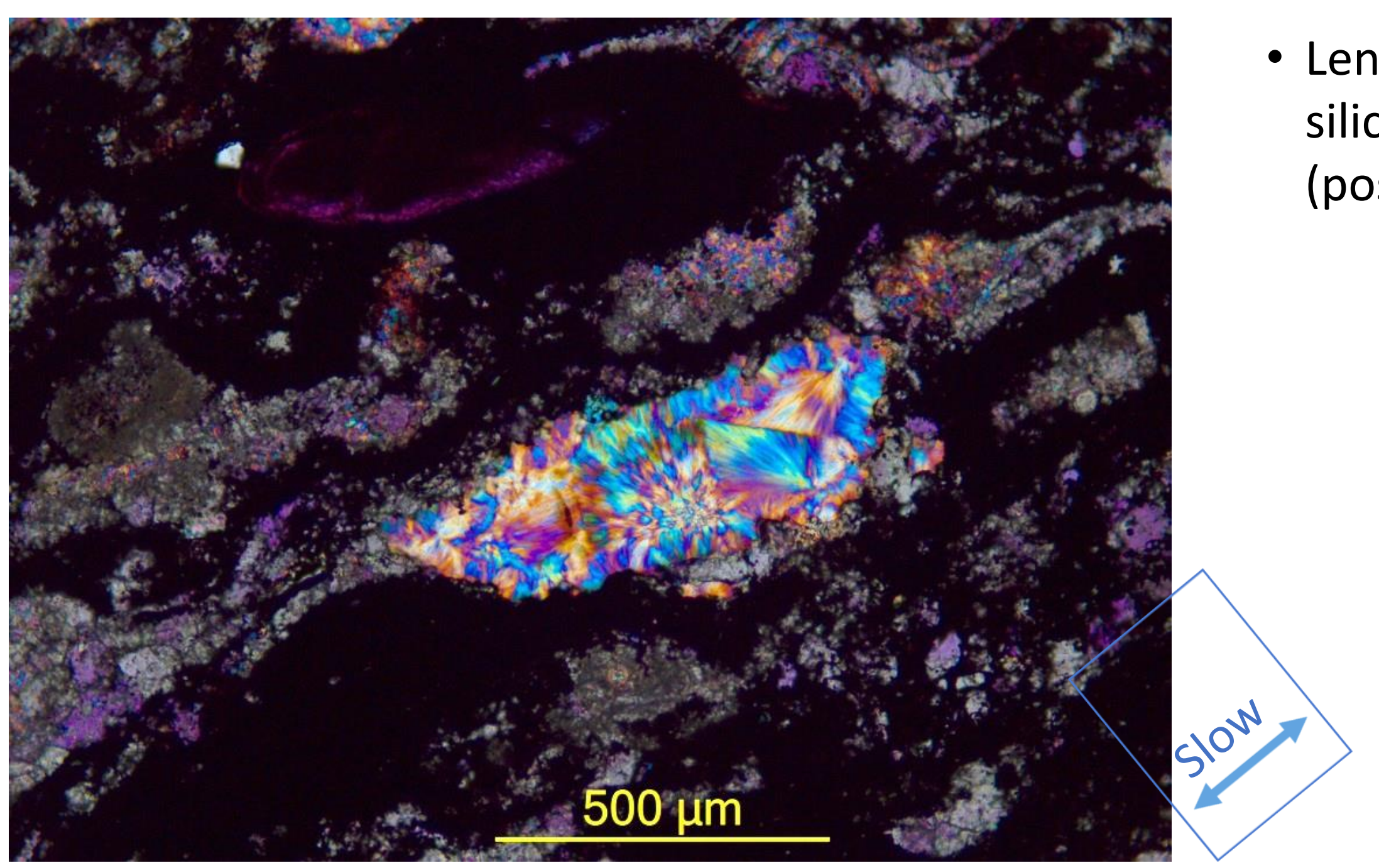

WV-WP1

(Whitmore Point) 


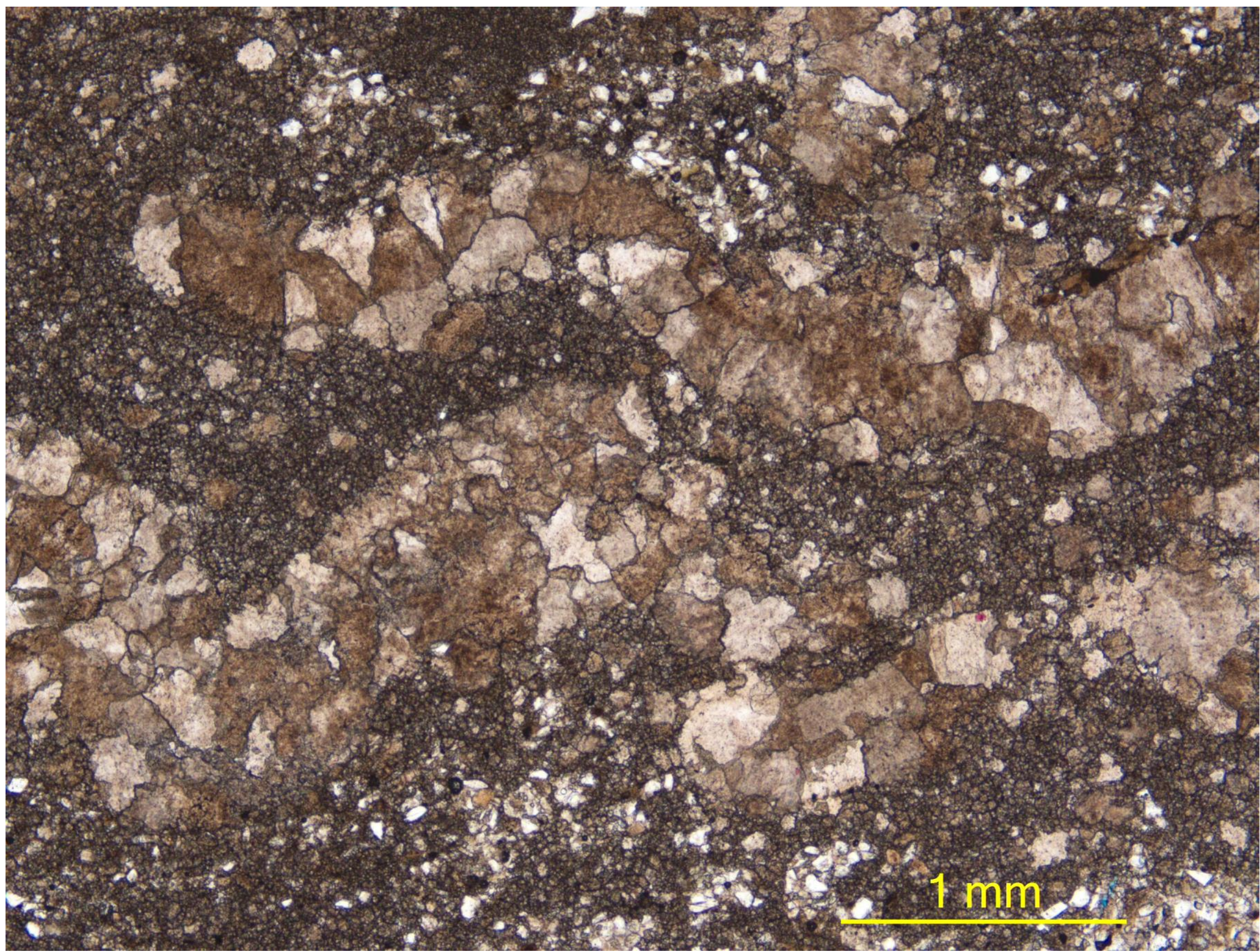

- Burrows prior to dolomitization

WV-3 (Kayenta) 
Dolomicrospar after calcite pseudomorphs after sulfate

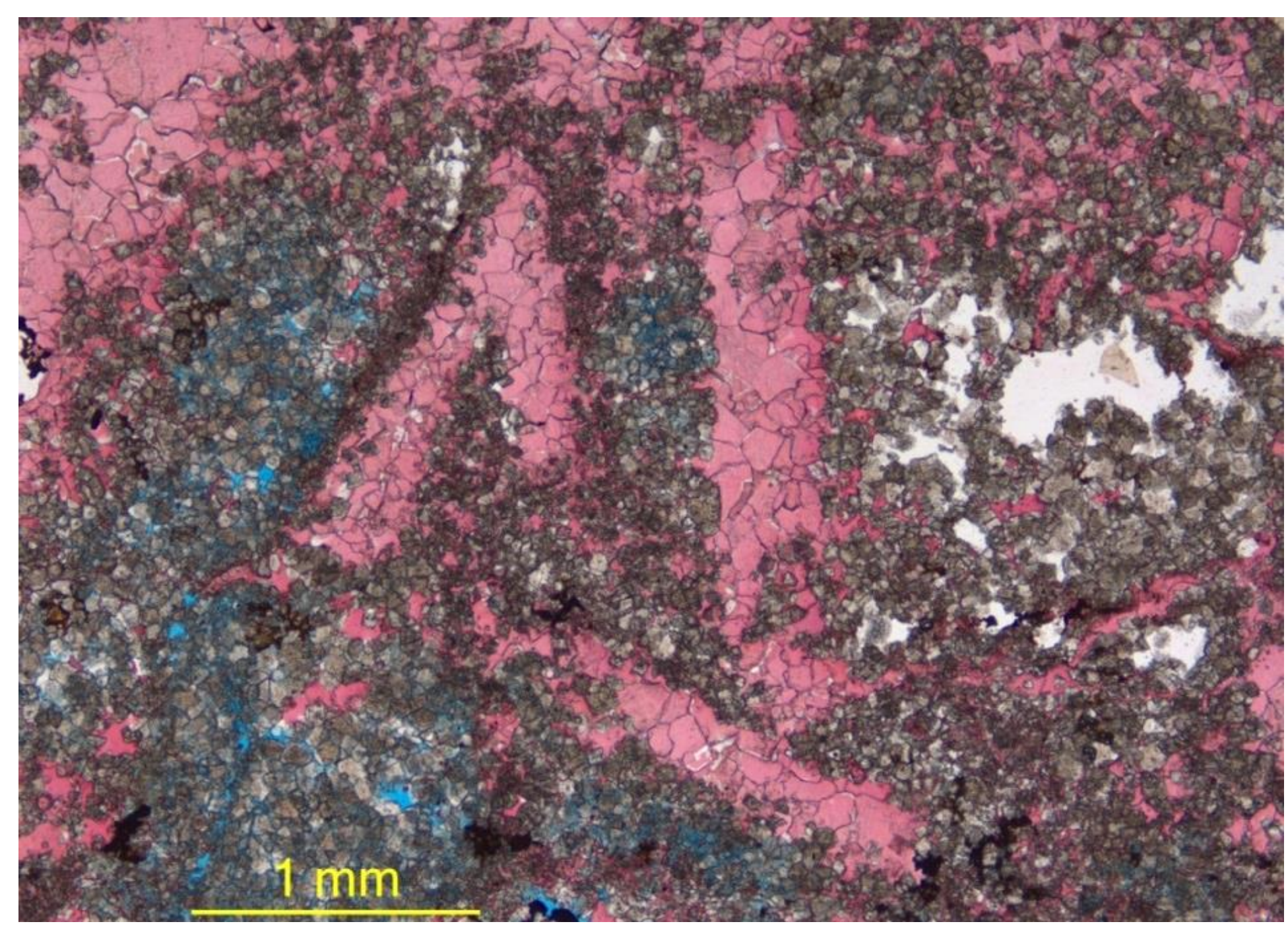

K (Kayenta),

St. George

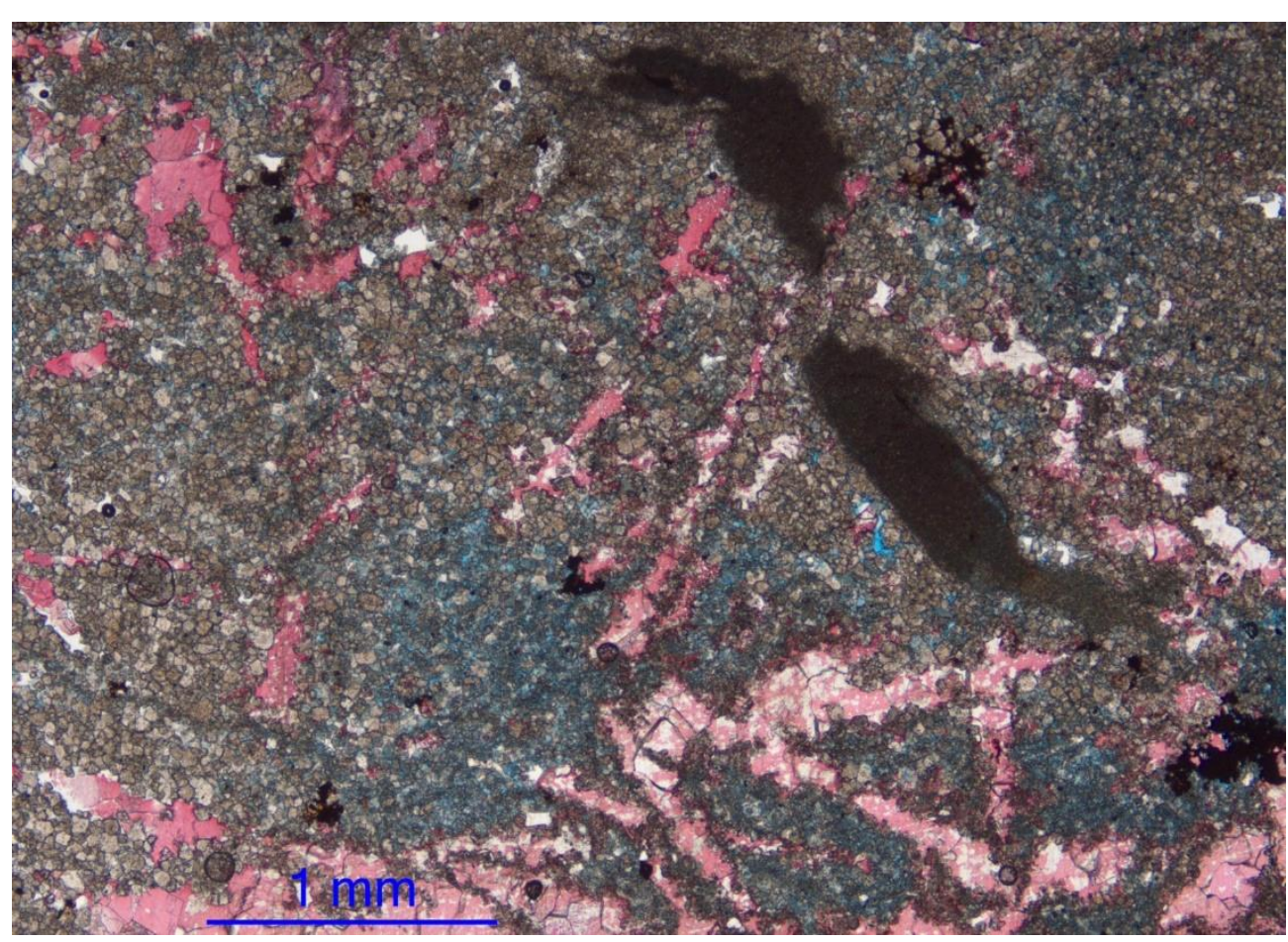




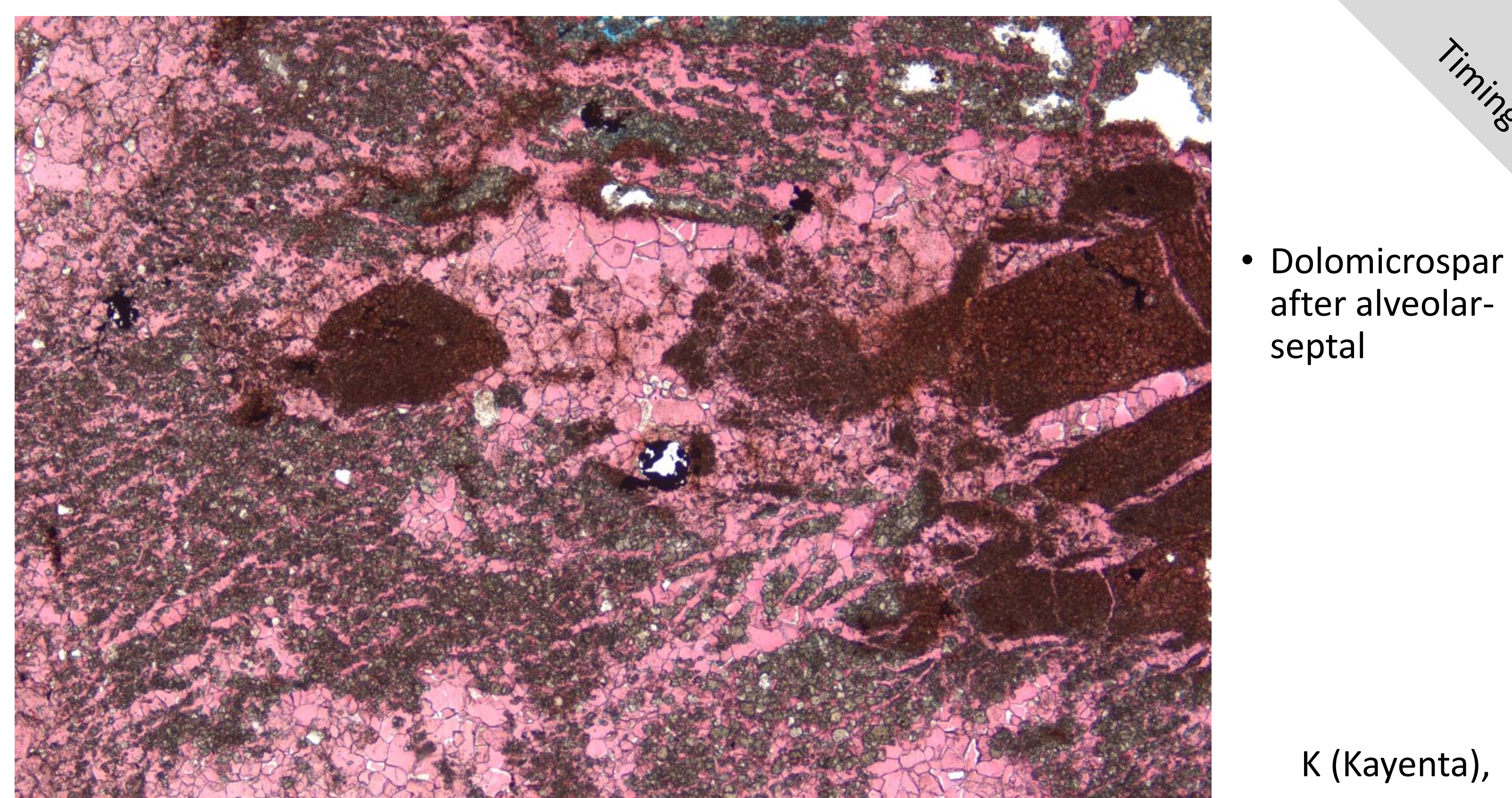

6.

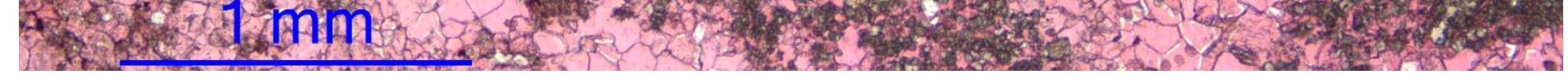

\section{St. George}




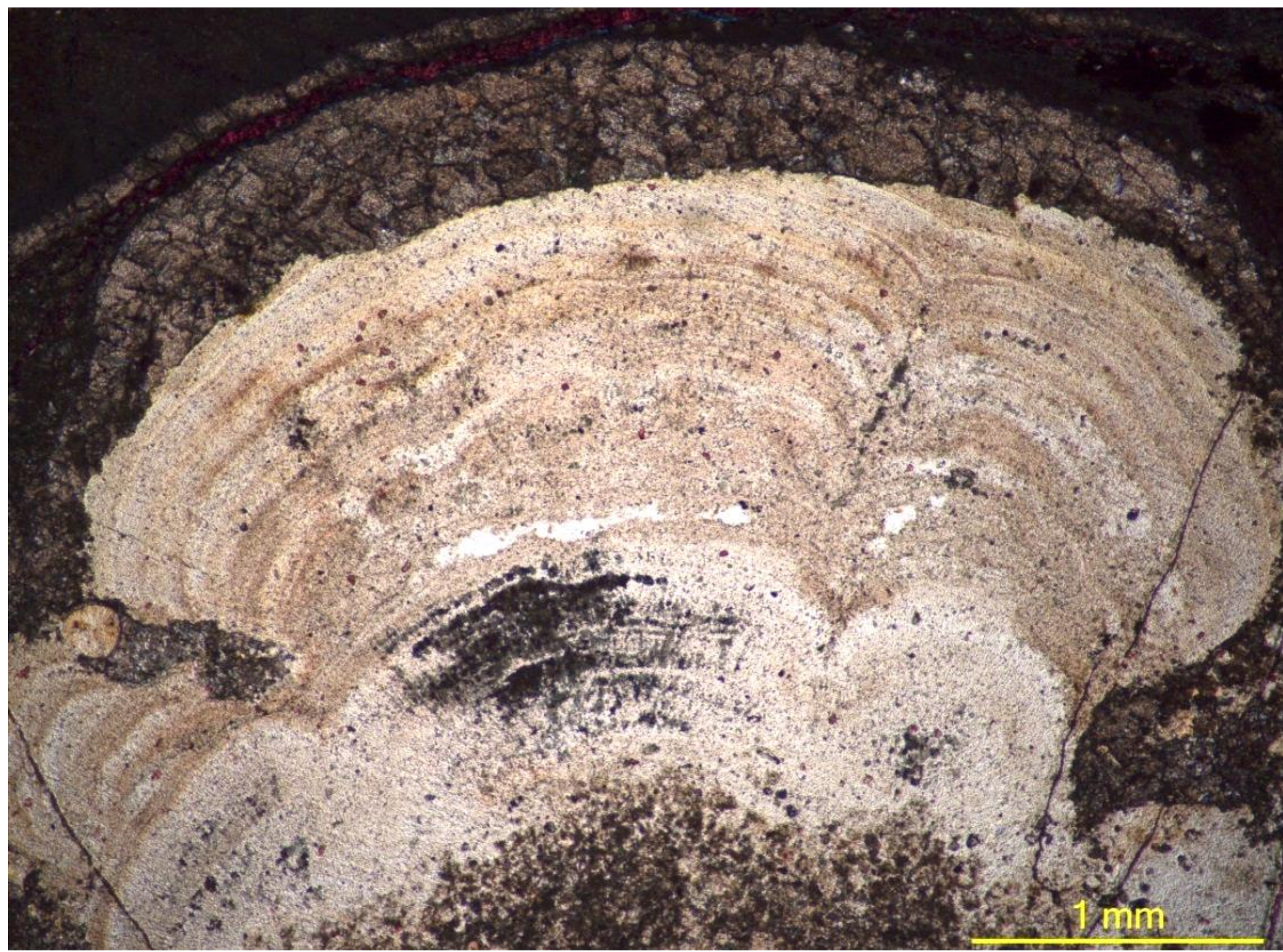

- Dolomitization after silicification

WV-WP1

(Whitmore Point) 


\section{Conclusions}

- Lacustrine depocenter and adjacent paleoenvironments.

- Low-grade, low-energy, frequent regressions (fine-grained, restricted shore units, pedogenesis and desiccation).

- Ephemeral lakes or closed hydrographic basin (desiccation, water chemistry, evaporation). Balanced-filled or underfilled lake successions.

- The above factors and the overall complex early diagenesis may suggest a semi-arid climate. 


\section{Acknowledgements}

- GSA Graduate Student Research Grant (2018).

- GSA's OTF travel grant (2018).

- LLU/GRI grant (2016).

- Ranjan Fernando, Gerald Bryant, and Wayne Kelln for support with research logistics.

- Loma Linda University for lab support. 


\section{References}

- Alonso-Zarza, A.M., Wright, V.P., 2010. Palustrine Carbonates. In: A.M. Alonso-Zarza \& L.H. Tanner (eds.); Carbonates in Continental Settings: Facies, Environments and Processes. Elsevier; Developments in Sedimentology 61, 103131.

- Bustillo, M.A., 2010. Silicification of Continental Carbonates. In: A.M. Alonso-Zarza \& L.H. Tanner (eds.); Carbonates in Continental Settings: Geochemistry, Diagenesis and Applications. Elsevier; Developments in Sedimentology 62 , 153-178.

- Folk, R.L., Pittman, J.S., 1971. Length-Slow Chalcedony: A New Testament for Vanished Evaporites. Journal of Sedimentary Petrology 41 (4): 1045-1058.

- John Warren's blog: http://www.saltworkconsultants.com/blog/tag/cauliflower chert/

- Milliken, K.L., 1979. The Silicified Evaporite Syndrome - Two Aspects of Silicification History of Former Evaporite Nodules from Southern Kentucky and Northern Tennessee. Journal of Sedimentary Petrology 49 (1): 245256.

- Vitkus, A.R., 2015. Unusual, Fossiliferous Concretions from the Lower Jurassic Moenave Formation of St. George, Utah, USA: Implications for Ancient Fish Mass Mortalities. Master of Science thesis, University of Colorado at Boulder. 